\title{
Dietary Supplements- Riding High on Perceptions and Practices in India
}

\author{
*Madhumita Dobe \\ Department of Health Promotion \& Education AIIH\&PH, Director-Professor \& Dean Head, India
}

Submission: May 04, 2017; Published: May 08, 2017

*Corresponding author: Madhumita Dobe, Department of Health Promotion \& Education AIIH\&PH, Director-Professor \& Dean Head, Kolkata, India, Email: madhumitadobe@gmail.com

\begin{abstract}
Common types of dietary supplements used in India are the multivitamin/multi-mineral products and health drinks along with herbs for treatment of health conditions and/or health promotion. Health consciousness, changing trends in population demographics, changing lifestyle, increasing consumer affluence and increased life expectancy is increasing use of dietary supplements. Large volume of dietary supplements is targeted at women and children in the country. Preventive dietary supplements for diseases such as cancer, diabetes, obesity and arthritis are also much sought after. There is low level of concern regarding potential adverse effects and drug-supplement interaction potential leading to over or improper consumption of dietary supplements.

People assume that because supplements are natural and are sold over the counter, they are completely safe, even in high doses. Increasing prevalence of dietary supplement raises concerns regarding the potential for drug-supplement interactions and other safety concerns. This is also true for herbal supplements. Moreover safety and dose are related. There is urgent need of standardization of active ingredients of supplements/nutraceutical, as well as quality assurance related to identity, purity, and bioavailability. Further policy interventions are necessary for addressing the dilemmas of claims and hidden information and better understanding of the dose- safety relationships for promoting public awareness on rational use of nutraceutical.
\end{abstract}

Keywords: Dietary Supplements; Use; Concerns; Dose-Safety; Natural; Mega-Dose, India

\section{Introduction}

Dietary supplements are those products which help us to fulfil our daily requirement of nutrients which otherwise not fulfilled by our routine diet. They include a wide array of nonfood, non-drug substances intended to supplement the diet, but are not intended to treat diseases or disorders of the human body [1]. The Indian definition for the dietary supplements as per the Food Safety and Security Act 2006 list down the ingredients that a product should have and it also specifies general properties of nutraceuticals [2]. Globally and in India, more than 50,000 dietary supplements are available. Basic Types of Supplements available include Multivitamins, Herbs and Health Drinks etc. These are available in various forms like powders, granules, tablets, capsules, liquids, etc. Common types of dietary supplements used in India are the multivitamin/ multi-mineral products and health drinks along with herbs for treatment of health conditions and/or health promotion [3].

\section{Increasing Use of Dietary supplements in India}

India is experiencing increasing number of nutrition linked non-communicable diseases. Health consciousness, changing trends in population demographics, changing lifestyle, increasing consumer affluence and increased life expectancy is increasing use of dietary supplements. Large numbers of dietary supplements are targeted at women and children in the country. Preventive dietary supplements for diseases such as cancer, diabetes, obesity and arthritis are also much sought after.

\section{Health Hazards of over or Improper Consumption}

Over or improper consumption of dietary supplements to treat self-diagnosed conditions and/or to promote health may be hazardous to health but there is low level of concern regarding potential adverse effects and drug-supplement interaction potential. A large number of vitamin supplements are available in the Indian market. It includes single-ingredient products and various combinations of vitamins, minerals, and other constituents. In a study [3] among single products, the maximum number was vitamin D3. Mostof the supplements were availableas combinations, with vitamin-minerals combinations constituting the maximum number. In a large number of products, amount of the vitamins was not specified. The most common formulation 
for oral administration was capsules. In the same study, majority of the supplements contained nutrient amounts higher than the recommended intakes and recommended dietary allowance. Such unsupervised intake of vitamins can pose a serious health risk in the susceptible population.

$50 \%$ of pregnant women are reported to use supplements but effects of most of these products on the foetus are not well documented and are a potential cause of concern [4]. These products contain one or more dietary ingredients such as a vitamin, mineral, herb or other botanical, amino acid, concentrate, metabolite, or combination of these ingredients. They may be purchased over the counter without a prescription. People often make the mistake of assuming that because supplements are sold over the counter, they are completely safe to take, even in high doses. Increasing prevalence of dietary supplement through prescription as well as OTC medication in India raises concerns regarding the potential for drug-supplement interactions and other safety concerns [5].

This is also true for herbal supplements which have also been witnessing rapid rise in demand with more and more people shifting away from synthetic products to natural products. There is an erroneous perception that as natural products, dietary supplements must be safer and more efficacious than conventional pharmaceuticals, but several large, controlled clinical trials have found that many supplements are inferior to conventional pharmaceuticals or placebo and/or have important safety concerns [6].

This is coupled with another common perception regarding herbal supplements that "Natural is safe" and "Natural is better". Yet it is well known that supplements that claim to be "all natural" are not always better or safer than refined or manufactured substances. Botanical supplements (such as garlic, ginger, ginkgo biloba etc.) are made of plant material, so many of them are sold as "natural" products but plants are made up of many chemicals. Some of these chemicals can be helpful while others are poisonous or can cause allergies in humans. Botanicals that are marketed as "all natural" are not always the most helpful ones, since they may not be refined to remove potentially harmful chemicals. Botanicals can contain any or all parts of the plant, including roots, stems, flowers, leaves, pollen, and juices. Different parts of plants can have very different effects on humans. For instance, dandelion root is a laxative (it causes bowel movements), while dandelion leaves contain a diuretic (a chemical that increases urination).

Moreover Safety and dose are related [7]. The leaves or roots of many plants can be safely taken in small amounts as an herb. But concentrated extracts sold as liquids or pills may contain the plant's chemicals in far greater amounts and may not be safe [7]. Knowing that a botanical has been used in folk or traditional medicine for thousands of years is not convincing proof that it is safe. Traditional medical systems thousands or even hundreds of years ago did not have the scientific methods to detect longterm side effects. Most herbs, plants, and other methods were used in traditional medicine systems to reduce symptoms or make the person feel better and if a plant seemed useful over the short term but actually increased the risk of chronic disease (like cancer, heart failure, or kidney failure) after years of use, those side effects would not have been noticed.

The question is whether an herb/plant used today is being used like it was traditionally - e.g. tea prepared from a certain plant might have been safely used in traditional Chinese medicine to treat occasional bouts of asthma when given by an experienced practitioner. On the other hand, daily use of much higher doses taken in a concentrated pill form with no expert supervision might be quite unsafe. Another prevalent perception regarding dietary supplements is that "More is better" [5]. Thus from 1990's we see a trend of "mega dosing" antioxidants like vitamin C, beta carotene, and vitamin E. Even though no scientific studies have ever proven that large doses of vitamin $\mathrm{C}$ can prevent or cure colds, many people still think this is true. Claims about other benefits of taking large doses of certain vitamins. Using large doses of vitamins to fight disease in humans is not supported by scientific evidence so far. Large doses of some vitamins or minerals have been shown to be dangerous and even toxic e.g. too much vitamin $\mathrm{C}$ can interfere with the body's ability to absorb copper. Too much phosphorous can inhibit the body's absorption of calcium. The body cannot get rid of large doses of vitamins $\mathrm{A}, \mathrm{D}$, and $\mathrm{K}$ and these can reach toxic levels when too much is taken.

\section{The Indian Nutraceutical Industry}

Dietary supplementary products come under the purview of the nutraceutical industry. According to a report by ASA \& Associates in February 2015 [8], nutraceutical industry in India is about USD 2.2 million and more focused in southern states of India. The Indian nutraceutical market is divided into functional food and beverages (68 per cent) and dietary supplements (32 per cent). Dietary supplements are projected to grow at the faster rate through 2017. Research also suggests that factors such as increasing obesity in the population and rising instances of diabetes and cardiovascular diseases and health awareness are pushing the use of nutraceutical products in India. As Indians are becoming conscious about their health, looks and feel, the market for dietary supplements, sports nutrition products, and weight loss products are also showing growth.

According to Health Outlook 2003 by KSA TECHNOPARK [9], covering major Tier-I and Tier-II cities, health counts about 9.4 percent share of the wallet of Indian consumer and is showing growth in last few years. Major categories where they spend are health supplements, health drinks, doctors and consultant's fees, medicines, medical insurance, regular check-ups etc. The liberty taken by the manufacturers in the garb of food safety laws to avoid rigours of drug laws acquires importance. There 
is a thin line of distinction between food/health supplement and drugs, particularly in a case where the contents and quantum of nutritional value and vitamins are specifically mentioned for various commercial reasons, making the categorisation highly subjective. There is no specific statutory or judicial yardstick available for being decisive on this aspect. Accordingly, the categorization of health and nutritional supplements as "food supplement" or "drug" would depend on the analysis of the ingredients/composition of the particular supplement as well as subjectivity of the authorities [10].

Lack of proper standardization in the market has been a major challenge in the market and has resulted in number of small companies offering products which are not up to the quality standards. About 60 to $70 \%$ of dietary supplements being sold across India are fake, counterfeit, unregistered and unapproved, besides it is extremely difficult to identify them, noted a recent Assoc ham-RNCOS joint study [11]. Other factors such as prevalence of counterfeit products and price skimming are few other challenges present in India Dietary Supplements Market [12]. By seeing this trend in the enormous growing field there is a compulsion for the regulation of the standard as well as quality and safety of the dietary supplements for public health concerns.

Recently, USFDA has warned India and other developing countries about selling of recalled samples of the dietary supplements from the US. There is no authority in India which can control the advertising regarding the dietary supplements as well as nutraceuticals where most of the human resources reside in the rural areas of the country, where most of them are illiterate. Any misleading information that has been printed on to the label of the dietary supplements may lead to the mass consumption of the supplements and that may cause a huge casualty to the human resource. Though National institute of Nutrition have given a dietary guideline of about 14 topics it is not enough for this enormous growing field and it needs an urgent attention of the government or the regulatory body in this direction [2].

\section{Conclusion}

In the context of such a scenario there is urgent need of Standardization of active ingredients, as well as quality assurance related to identity, purity, and bioavailability, which till date is largely left only up to the information provided by individual manufacturers [13]. Since the establishment of the AYUSH Ministry, there has been increased information availability concerning the appropriate use and place in therapy of herbal products and dietary supplements [14]. Further policy interventions are necessary for addressing the dilemmas of claims and hidden information and better understanding of the dose- safety relationships for promoting public awareness on rational use of nutraceutical.

\section{Conflict of Interest}

No economic interest or any conflict of interest exists for the author.

\section{References}

1. Dietary supplement (2017).

2. Mohamed Naeem Devla, Sanjeev R Acharya, Niyati S Acharya, Vimal Kumar (2011) Dietary supplements: A Legal Status in India \& in Foreign countries. International Journal of Pharmacy and Pharmaceutical Sciences 3(3): 1-12.

3. Preeta K Chugh, Y Lhamo (2012) An Assessment of Vitamin Supplements in the Indian Market - Indian J Pharm Sci 74(5): 469-473.

4. Punam Sachdeva, BG Patel, BK Patel (2009) Drug Use in Pregnancy; a Point to Ponder!. Indian J Pharm Sci71(1): 1-7.

5. Common misconceptions about dietary supplements (2015) American Cancer Society, USA.

6. Christopher Owens, Tiffanie Toone, Michelle Steed Ivie (2014) A Survey of Dietary Supplement Knowledge, Attitudes, and Use in a Rural Population.Journal of Nutrition \& Food Sciences 4: 304.

7. Dietary Supplements: What Is Safe? (2017) American Cancer Society, USA.

8. ASA \& Associates (2015) A brief report on Nutraceutical products in India.

9. KSA Techno park (2003) A Study on Consumer Behaviour towards Health and Dietary Supplements by Health.

10.Vijay Pal Dalmia (2013) Law of Nutritional \& Supplemental Food Products In India - The Conflict: Food Or Drug? Mondaq Connecting Knowledge to people India.

11. Assocham IndiaUpto 70\% fitness supplements sold in Indian market are fake: Study. Business Standard, USA.

12. India Dietary Supplements Market Forecast \& Opportunities, 2021. TechSci Research Report 12, PR Newswire, UK.

13. Ramesh C Gupta (2016) Nutraceutical: Efficacy, Safety and Toxicity. Academic press, USA.

14. AYUSH (2016) National Health Portal of India. India Government, India. 
This work is licensed under Creative Commons Attribution 4.0 Licens

DOI: 10.19080/JOJPH.2017.01.555573

\section{Your next submission with Juniper Publishers will reach you the below assets}

- Quality Editorial service

- Swift Peer Review

- Reprints availability

- E-prints Service

- Manuscript Podcast for convenient understanding

- Global attainment for your research

- Manuscript accessibility in different formats

( Pdf, E-pub, Full Text, Audio)

- Unceasing customer service

Track the below URL for one-step submission https://juniperpublishers.com/online-submission.php 